\title{
Factors influencing length of survival in ambulatory palliative care - a cross sectional study based on secondary data
}

\author{
Johannes Just ${ }^{1 *}$, Marie-Therese Schmitz ${ }^{2}$, Ulrich Grabenhorst ${ }^{3}$, Thomas Joist ${ }^{3}$, Kirsten Horn ${ }^{3}$, Bettina Engel ${ }^{4}$ and
} Klaus Weckbecker ${ }^{1}$

\begin{abstract}
Background: Quality of life and patient self-determination are key elements in successful palliative care. To achieve these goals, a robust prediction of the remaining survival time is useful as it can provide patients and their relatives with information for individual goal setting including appropriate priorities. The Aim of our study was to assess factors that influence survival after enrollment into ambulatory palliative care.

Methods: In this cross-sectional, multicenter study ( $n=14$ study centers) clinical records of all palliative care patients who were treated in 2017 were extracted and underwent statistical analysis. The main outcome criterion was the association of survival time with clinical characteristics such as age, type of disease, symptoms and performance status.

Results: A total of 6282 cases were evaluated. Median time of survival was 26 days (95\% Cl: 25-27 days). The strongest association for an increased hazard ratio was found for the following characteristics: moderate/severe weakness (aHR: 1.91; $95 \%$ Cl: 1.27-2.86) Karnofsky score 10-30 (aHR: 1.80; $95 \%$ Cl: 1.67-1.95), and age > 85 (aHR: $1.50 ; 95 \% \mathrm{Cl}: 1.37-1.64)$. Surprisingly, type of disease (cancer vs. non-cancer) was not associated with a change in survival time (aHR: 1.03; $95 \% \mathrm{Cl}$ : 0.96-1.10).
\end{abstract}

Conclusions: In this cross-sectional study, the most relevant predictor for a short survival time in specialized ambulatory palliative care was the performance status while type of disease was irrelevant to survival.

Keywords: Palliative Care, Survival, Ambulatory Care, non-cancer disease

\section{Background}

Quality of life and patient self-determination are key elements in successful palliative care $[1,2]$. These goals can be helped by a robust prognosis as it can provide patients and their relatives with information for individual goal setting including appropriate priorities and expectations of care and can help health-care professionals with patient-centered clinical decision making [3-7].

\footnotetext{
* Correspondence: johannes.just@uni-wh.de

'Institute of General Practice and Interprofessional Care Witten/Herdecke University, Alfred-Herrhausen-Straße 50, 58453 Witten, Germany

Full list of author information is available at the end of the article
}

Despite the importance of prognosis for successful palliative care, clinicians are sometimes reluctant to give a precise prognosis of medical outcomes, especially death $[8,9]$. Physicians reported poor training, lack of data and difficulties in formulating and communicating as major problems in delivering a prognosis [10]. Furthermore, they were worried that patients and colleagues may judge them poorly when the prognosis is incorrect. Their worries are understandable, as prognosis in terminally ill patients is complicated and often inaccurate [11].

C C The Author(s). 2021 Open Access This article is licensed under a Creative Commons Attribution 4.0 International License, which permits use, sharing, adaptation, distribution and reproduction in any medium or format, as long as you give appropriate credit to the original author(s) and the source, provide a link to the Creative Commons licence, and indicate if changes were made. The images or other third party material in this article are included in the article's Creative Commons licence, unless indicated otherwise in a credit line to the material. If material is not included in the article's Creative Commons licence and your intended use is not permitted by statutory regulation or exceeds the permitted use, you will need to obtain permission directly from the copyright holder. To view a copy of this licence, visit http://creativecommons.org/licenses/by/4.0/ The Creative Commons Public Domain Dedication waiver (http://creativecommons.org/publicdomain/zero/1.0/) applies to the data made available in this article, unless otherwise stated in a credit line to the data. 
Although data on predictive factors for an impending death are limited, some clinical factors associated with an increased risk for an impending death have been identified and may help clinicians to improve the accuracy of their prognosis. They include symptoms associated with cancer anorexia-cachexia syndrome, dyspnea and delirium but were mostly investigated in cancer patients $[5,12]$. A retrospective cohort study from the UK with 4650 patients showed that days in palliative care were especially limited for those patients with noncancer disease and older age [13].

While a reliable prediction to the day of death is yet out of reach, identifying further patterns associated with an impending end-of-life situation may be a next step to help physicians to improve the quality of prognosis, steering them away from existing coping strategies like avoidance, optimism and vagueness [8-11]. In order to do so, more data from large palliative care patient collectives with cancer and non-cancer disease is needed.

Our aim was to analyze clinical data from ambulatory palliative care providers in Germany in order to identify clinical factors that influence survival rates of terminally ill-patients with cancer and non-cancer disease, including basic characteristics like age, burden of symptoms and performance status at the time of submission to palliative care.

In Germany, patients with a life-limiting disease and a high symptom burden can be referred to a high-quality, visit-based ambulatory palliative care system called SAPV ("Spezialisierte Ambulante Palliativ-Versorgung = spezialiced ambulatory palliative care), which delivers specialised medical and nursing care services and is covered by the statutory health care system. The main aim of SAPV is to enable these patients to remain in their home or family environment despite complex treatment needs. SAPV is designed to deal with disease-related crisis situations that might otherwise lead to undesired and stressful hospital admissions in patients where curative treatment is no longer an option. To do so, the service providers must have appropriate training and must guarantee 24-hour availability seven days a week [14, 15].

\section{Methods}

\section{Study design}

We conducted a retrospective cross-sectional analysis from anonymized routine treatment data aiming to identify clinical factors that influence survival rates of terminally ill-patients with cancer and non-cancer disease.

\section{Setting and locations}

Data was retrieved from 14 SAPV providers in the administrative "Nordrhein-region", Germany. Each provider is certified for a defined geographic area. Cumulatively, those 14 providers cover appx. 5 million
$(52.6 \%)$ of the 9.5 million inhabitants in the "Nordrhein-region" [16].

\section{Data sources and measurement}

The patient data was recorded by the SAPV providers in the Digital Documentation System Palliative Care ${ }^{\circ}$ (ISPC) by the company SmartQ-Softwaresysteme GmbH or PalliDoc ${ }^{\circ}$ by the company StatConsult (Gesellschaft für klinische und Versorgungsforschung $\mathrm{mbH}$ ) as part of routine case documentation.

Data extraction was coordinated by the Association of SAPV-Teams in North Rhine e.V. (VSTN = Verbund der SAPV-Teams Nordrhein e.V.) of which all participating data providers are a member. The entire patient information of the electronic files of the 14 providers was extracted from ISPC ${ }^{\circ}$ and PalliDoc ${ }^{\circ}$ in anonymised form on the patient as well as the provider level. Merging and data quality management was performed by StatConsult, a software developer and contract institute for tasks in clinical research, development and health services research.

\section{Ethical considerations}

The requirements of the current version of the Declaration of Helsinki have been observed. The responsible ethics committee of the North Rhine Medical Association evaluated the project and issued no objection (process number 57/2017).

\section{Participants and case definitions}

In order to distinguish cancer from non-cancer patients, all patients with an admission diagnosis or main diagnosis according to ICD-10 C00 - D48 were labeled "cancer patients". A co-diagnosis of cancer was considered to be secondary for enrollment into SAPV (e.g. admission diagnosis dyspnea, primary diagnosis heart failure, secondary diagnosis prostate cancer).

The dataset includes all patients who were under treatment in 2017. This means that cases that started before 2017 or continued into 2018 were also part of the dataset.

SAPV is not always continuous and can be paused or completely ended for various reasons e.g. hospitalization, transfer to hospice or improvement of symptom burden due to therapy.

About one third of the patients in our dataset showed several treatment periods varying in length of treatment as well as gap-period. In order to include these patients in the analysis, we decided to merge cases in which the treatment gaps did not exceed 13 days. The clinical rationale was that short gaps mostly derived from hospital visits for specialised procedures such as palliative chemotherapy or erythrocyte transfusion and were therefore caused by accounting requirements and not 
because patients ceased to have an indication for ambulatory palliative care. The 13 days cut-off was chosen based on expert opinion as well as coverage of $75 \%$ of cases with a treatment gap. Naturally, much larger treatment gaps occurred in a minor amount of cases which we attributed to an overall improvement in symptom burden after an initial crisis situation, which enabled the patient to return into general primary care for a period of time. In these cases, only treatment periods after the last treatment-gap $>13$ days were included. We performed a sensitivity analysis to control for relevant differences between patients with and without a treatment gap $>13$ days.

\section{Quantitative variables and statistical analysis}

Descriptive statistics were used to present characteristics of the study population. The characteristics included: Gender, age, Karnofsky-score, pain, dyspnea, confusion, loss of appetite, weakness, emesis, nausea. Categorical variables were summarized by absolute and relative frequencies, e.g. the Karnofsky score, a performance scale used to quantify cancer patients' general well-being and activities of daily life ranging from 0 (death) to 100 (perfect health) was categorised as low when the patient was bedridden (10-30). Symptoms were assessed by palliative care specialists using 5- and 10-point Likert-Scales. In an attempt to harmonize reporting between the different teams, they were redistributed upon data extraction and grouped as none, mild, moderate and severe. Because of the distribution pattern, moderate and severe symptoms were later pooled for statistical analysis as it was clinically acceptable and led to a similar group sizes. Kaplan-Meier estimates were used to visualize the observed time to death in different patient groups (cancer/non-cancer, dichotomized Karnofsky-score and age). Additionally, the median survival time including 95\% confidence intervals (CI) was determined. In order to further analyse the association between the survival time of the patients and several variables (cancer/non-cancer, Karnofsky-score, age, gender and symptoms such as pain, dyspnea, confusion, loss of appetite, weakness, emesis and nausea), a Cox proportional hazard model was used and hazard ratios (HR) as well as adjusted hazard ratios (aHR) with $95 \%$ CI were reported. The multivariable Cox model included all aforementioned variables. In regression analysis, missing values within the independent variables were assigned to the most frequent category only when the amount of missing values was below a threshold of $5 \%$ (only for cancer/non-cancer groups and gender). Otherwise missing values were summarized into a separate category. All analyses were carried out using $\mathrm{R}$ (version 4.0.2) and SAS 9.4. The documentation of the analysis is based on the recommendations of the STROBE statement [17].

\section{Results}

Within the year 2017, a total of 6828 patients were treated by 14 SAPV teams in North Rhine-Westphalia of which $75.3 \%(n=5141)$ died within their treatment period which amounts to roughly $9 \%$ of the total annual death toll in the region [18]. Most patients had one single treatment period prior to death $(67.9 \%)$, a further $21.5 \%$ of patients had two or more consecutive treatment periods with only short gaps $(<13$ days) that were therefore combined for analysis. The number of cases where prior treatment periods were excluded because of a longer treatment gap ( $>13$ days) was $10.6 \%$. Patients with no or short treatment gaps were slightly older and showed a higher rate of cancer disease compared to those with longer treatment gaps (median age 75.3 vs. 71.8 years; rate of cancer-disease 74.7 vs. 80.0 ).

An overview of the basic sociodemographic data as well as basic functionality indicators and symptom burden of the complete study population is given in Table 1:

In general, patients with non-cancer disease showed a higher burden of symptoms with increased rates of moderate and severe confusion, dyspnea, loss of appetite and weakness, while patients with cancer disease showed increased rates of emesis and nausea. However, the arguably most distressful symptom, pain, was almost equally distributed between both groups.

The overall median survival based on the treatment periods was 26 days, meaning that $50 \%$ of patients died within the first 26 days (95\% CI: $25-27$ days) while $25 \%$ died within 8 days and $75 \%$ within 75 days. A visual representation of the Kaplan-Meier estimate up to 60 days is given in Fig. 1, Curve A.

Additionally, Kaplan-Meier Curves for potentially relevant influencing factors on survival were created (Fig. 1 Kaplan-Meier Curves B, C, D). The choice of influencing factors was literature based $[5,12,19]$.

Figure 1 legend: missing values are not shown (Fig. 1 a: $\mathrm{n}=0 \quad(0.0 \%) ;$ Fig. 1 b: $\mathrm{n}=23 \quad(0.3 \%) ;$ Fig. 1 c: $\mathrm{n}=0$ (0.0\%); Fig. 1d: $\mathrm{n}=2812(41.2 \%)$ ).

As we suspected a strong overlap between several characteristics (e.g. "age" and "Karnofsky-Score"), we used a cox proportional hazard model in order to adjust for the individual effects of influencing factors. Thus, we were able to show that the functional status as represented by weakness and the Karnofsky-score upon enrollment in SAPV was the most relevant prognostic factor, regardless of type of disease. All hazard ratios are shown in Table 2.

\section{Discussion}

Our data shows that patients with non-cancer disease were admitted to SAPV with a much lower performance status, which in turn was the strongest predictor of a 
Table 1 Characteristics of the study population divided by cancer and non-cancer disease

\begin{tabular}{|c|c|c|c|c|c|c|}
\hline \multirow{2}{*}{$\begin{array}{l}\text { Variable } \\
\text { Gender }\end{array}$} & \multicolumn{2}{|c|}{$\begin{array}{l}\text { Total } \\
(n=6828)\end{array}$} & \multicolumn{2}{|c|}{$\begin{array}{l}\text { Cancer }^{a} \\
(n=5140)\end{array}$} & \multicolumn{2}{|c|}{$\begin{array}{l}\text { Non-cancer }{ }^{a} \\
(n=1665)\end{array}$} \\
\hline & $\mathrm{n}$ & $\%$ & $\mathrm{n}$ & $\%$ & $n$ & $\%$ \\
\hline Male & 3337 & 48.9 & 2632 & 51.3 & 696 & 41.9 \\
\hline Female & 3482 & 51.0 & 2502 & 48.7 & 966 & 58.1 \\
\hline Missing & 9 & 0.1 & 6 & & 3 & \\
\hline \multicolumn{7}{|l|}{ Age, years } \\
\hline$<65$ & 1409 & 20.6 & 1257 & 24.5 & 148 & 8.9 \\
\hline $65-74$ & 1416 & 20.7 & 1203 & 23.4 & 208 & 12.5 \\
\hline $75-84$ & 2349 & 34.4 & 1820 & 35.4 & 522 & 31.4 \\
\hline$\geq 85$ & 1654 & 24.2 & 860 & 16.7 & 787 & 47.3 \\
\hline \multicolumn{7}{|l|}{ Karnofsky score } \\
\hline $10-30$ & 2124 & 31.1 & 1242 & 42.1 & 879 & 82.8 \\
\hline $40-100$ & 1892 & 27.7 & 1708 & 57.9 & 182 & 17.2 \\
\hline Missing & 2812 & 41.2 & 2190 & & 604 & \\
\hline \multicolumn{7}{|l|}{ Pain } \\
\hline No & 1155 & 16.9 & 883 & 22.2 & 267 & 21.8 \\
\hline Mild & 1723 & 25.2 & 1339 & 33.6 & 382 & 31.2 \\
\hline Moderate/severe & 2341 & 34.3 & 1758 & 44.2 & 575 & 47.0 \\
\hline Missing & 1609 & 23.6 & 1160 & & 441 & \\
\hline \multicolumn{7}{|l|}{ Dyspnea } \\
\hline No & 1812 & 26.5 & 1374 & 32.6 & 431 & 33.2 \\
\hline Mild & 1821 & 26.7 & 1473 & 34.9 & 347 & 26.7 \\
\hline Moderate/severe & 1895 & 27.8 & 1372 & 32.5 & 520 & 40.1 \\
\hline Missing & 1300 & 19.0 & 921 & & 367 & \\
\hline \multicolumn{7}{|l|}{ Confusion } \\
\hline No & 2672 & 39.1 & 2356 & 59.9 & 313 & 24.8 \\
\hline Mild & 1040 & 15.2 & 812 & 20.7 & 226 & 17.9 \\
\hline Moderate/severe & 1489 & 21.8 & 763 & 19.4 & 721 & 57.2 \\
\hline Missing & 1627 & 23.8 & 1209 & & 405 & \\
\hline \multicolumn{7}{|l|}{ Loss of appetite } \\
\hline No & 670 & 9.8 & 517 & 11.6 & 152 & 11.3 \\
\hline Mild & 1002 & 14.7 & 826 & 18.5 & 175 & 13.0 \\
\hline Moderate/severe & 4146 & 60.7 & 3113 & 69.9 & 1021 & 75.7 \\
\hline Missing & 1010 & 14.8 & 684 & & 317 & \\
\hline \multicolumn{7}{|l|}{ Weakness } \\
\hline No & 48 & 0.7 & 43 & 0.9 & 5 & 0.4 \\
\hline Mild & 566 & 8.3 & 511 & 11.2 & 54 & 3.9 \\
\hline Moderate/severe & 5368 & 78.6 & 4017 & 87.9 & 1334 & 95.8 \\
\hline Missing & 846 & 12.4 & 569 & & 272 & \\
\hline \multicolumn{7}{|l|}{ Emesis } \\
\hline No & 4033 & 59.1 & 2986 & 77.4 & 1040 & 87.5 \\
\hline Mild & 595 & 8.7 & 506 & 13.1 & 89 & 7.5 \\
\hline Moderate/severe & 427 & 6.3 & 368 & 9.5 & 59 & 5.0 \\
\hline Missing & 1773 & 26.0 & 1280 & & 477 & \\
\hline
\end{tabular}


Table 1 Characteristics of the study population divided by cancer and non-cancer disease (Continued)

\begin{tabular}{|c|c|c|c|c|c|c|}
\hline Variable & $\begin{array}{l}\text { Total } \\
(n=6828)\end{array}$ & & $\begin{array}{l}\text { Cancer }^{\mathrm{a}} \\
(n=5140)\end{array}$ & & $\begin{array}{l}\text { Non-cancer }^{\mathrm{a}} \\
(n=1665)\end{array}$ & \\
\hline \multicolumn{7}{|l|}{ Nausea } \\
\hline No & 3097 & 45.4 & 2181 & 53.4 & 911 & 75.6 \\
\hline Mild & 1301 & 19.1 & 1108 & 27.1 & 191 & 15.9 \\
\hline Moderate/severe & 899 & 13.2 & 796 & 19.5 & 103 & 8.5 \\
\hline Missing & 1531 & 22.4 & 1055 & & 460 & \\
\hline
\end{tabular}

Relative frequencies refer to non-missing cases only. There were $n=23$ patients with missing data on diagnoses ( $0.3 \%)$

short life expectancy. The burden of symptoms upon enrollment into SAPV was at most slightly higher in patients with non-cancer disease but the most important symptom in palliative care, pain, was equally distributed between patients with and without cancer disease.

The strength of this analysis includes the multi-center approach and the high number of cases. To our knowledge, it is the largest collective of cancer and noncancer patients in ambulatory palliative care that has been studied regarding survival rates to date.

In terms of generalizability, the multi-center approach makes it representative for the Nordrhein-region and relatively representative for SAPV in Germany as a whole. As data was extracted from health care data

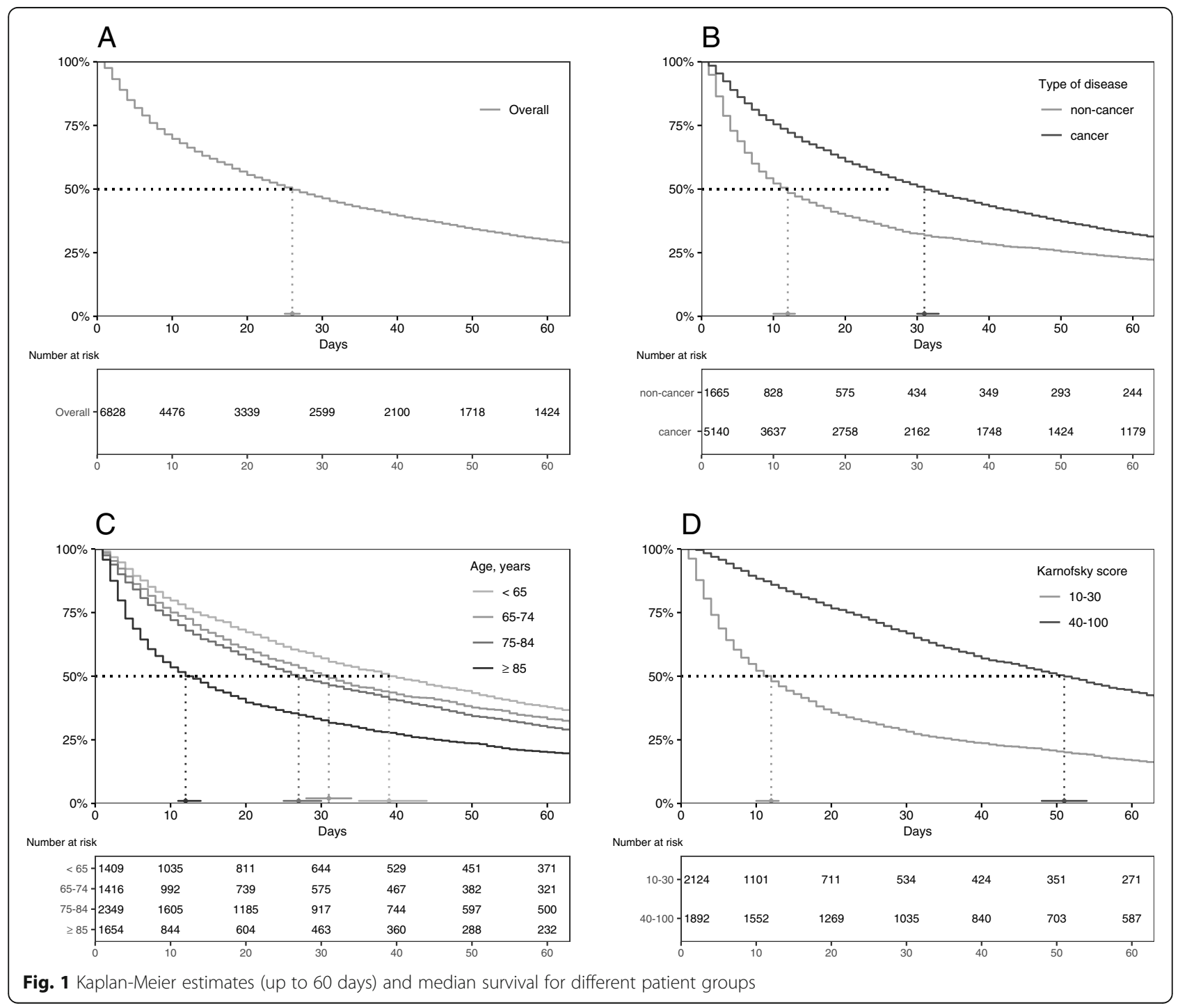


Table 2 Cox-hazard regression model

\begin{tabular}{|c|c|c|c|c|}
\hline Variable & Unadjusted HR & $95 \%-\mathrm{Cl}$ & Adjusted HR & $95 \%-\mathrm{Cl}$ \\
\hline \multicolumn{5}{|l|}{ Gender $^{a}$} \\
\hline Male & Reference & - & Reference & - \\
\hline Female & 0.95 & $0.90-1.00$ & 0.88 & $0.83-0.93$ \\
\hline \multicolumn{5}{|l|}{ Age, years } \\
\hline$<65$ & Reference & - & Reference & - \\
\hline $65-74$ & 1.18 & $1.08-1.28$ & 1.09 & $1.00-1.19$ \\
\hline $75-84$ & 1.25 & $1.16-1.35$ & 1.15 & $1.06-1.24$ \\
\hline$\geq 85$ & 1.82 & $1.68-1.98$ & 1.50 & $1.37-1.64$ \\
\hline \multicolumn{5}{|l|}{ Diagnosis $^{\mathrm{a}}$} \\
\hline Cancer & Reference & - & Reference & - \\
\hline Non-cancer & 1.45 & $1.36-1.54$ & 1.03 & $0.96-1.10$ \\
\hline \multicolumn{5}{|c|}{ Karnofsky performance score } \\
\hline $40-100$ & Reference & - & Reference & - \\
\hline $10-30$ & 2.29 & $2.13-2.46$ & 1.80 & $1.67-1.95$ \\
\hline Missing & 1.44 & $1.35-1.55$ & 1.21 & $1.12-1.31$ \\
\hline \multicolumn{5}{|l|}{ Pain } \\
\hline No & Reference & - & Reference & - \\
\hline Mild & 1.08 & $0.98-1.17$ & 1.02 & $0.94-1.12$ \\
\hline Moderate/severe & 1.31 & $1.21-1.42$ & 1.14 & $1.05-1.25$ \\
\hline Missing & 1.39 & $1.27-1.52$ & 0.96 & $0.86-1.07$ \\
\hline \multicolumn{5}{|l|}{ Dyspnea } \\
\hline No & Reference & - & Reference & - \\
\hline Mild & 1.00 & $0.92-1.07$ & 1.01 & $0.93-1.09$ \\
\hline Moderate/severe & 1.26 & $1.17-1.36$ & 1.16 & $1.08-1.25$ \\
\hline Missing & 1.67 & $1.54-1.82$ & 1.18 & $1.04-1.35$ \\
\hline \multicolumn{5}{|l|}{ Confusion } \\
\hline No & Reference & - & Reference & - \\
\hline Mild & 1.35 & $1.25-1.47$ & 1.10 & $1.01-1.20$ \\
\hline Moderate/severe & 1.88 & $1.75-2.02$ & 1.33 & $1.23-1.44$ \\
\hline Missing & 1.66 & $1.54-1.79$ & 1.15 & $1.02-1.30$ \\
\hline \multicolumn{5}{|l|}{ Loss of appetite } \\
\hline No & Reference & - & Reference & - \\
\hline Mild & 1.02 & $0.90-1.15$ & 1.02 & $0.90-1.15$ \\
\hline Moderate/severe & 1.70 & $1.54-1.87$ & 1.44 & $1.30-1.60$ \\
\hline Missing & 2.34 & $2.08-2.63$ & 1.31 & $1.09-1.56$ \\
\hline \multicolumn{5}{|l|}{ Weakness } \\
\hline No & Reference & - & Reference & - \\
\hline Mild & 1.20 & $0.80-1.82$ & 1.56 & $1.03-2.37$ \\
\hline Moderate/severe & 2.20 & $1.48-3.29$ & 1.91 & $1.27-2.86$ \\
\hline Missing & 3.81 & $2.53-5.72$ & 2.78 & $1.80-4.28$ \\
\hline \multicolumn{5}{|l|}{ Emesis } \\
\hline No & Reference & - & Reference & - \\
\hline Mild & 1.15 & $1.05-1.27$ & 1.02 & $0.91-1.13$ \\
\hline Moderate/severe & 1.26 & $1.13-1.40$ & 1.13 & $0.99-1.29$ \\
\hline
\end{tabular}


Table 2 Cox-hazard regression model (Continued)

\begin{tabular}{lllll}
\hline Variable & Unadjusted HR & $\mathbf{9 5} \%-\mathbf{C l}$ & Adjusted HR & 95 \%-Cl \\
\hline Missing & 1.43 & $1.34-1.53$ & 0.98 & $0.86-1.12$ \\
Nausea & & & Reference \\
No & Reference & - & 0.96 & - \\
Mild & 1.01 & $0.94-1.09$ & 0.99 & $0.89-1.05$ \\
Moderate/severe & 1.10 & $1.01-1.20$ & 1.21 & $1.05-1.39$ \\
Missing & 1.58 & $1.47-1.69$ & & \\
\hline
\end{tabular}

${ }^{a}$ Female includes $n=9$ patients with missing values on gender; cancer includes $n=23$ patients with missing values on diagnosis ref. reference; $H R$ hazard ratio; $\mathrm{Cl}$ confidence interval

instead of insurance data, it covers the whole population and doesn't exclude patients with private insurance. SAPV is a well-funded and well received instrument of care that is accessible through statutory health insurance as well as private insurance and therefore is theoretically accessible to every German citizen. So while the actual survival rates of patients may not be comparable to patients who receive a different type of care in other parts of the world, we assume that the influencing factors for a decrease in survival time may be generalizable to an ambulatory care setting for patients with a life-limiting disease and a high symptom burden .

In terms of validity, we expect the data to be of decent quality, as it represents clinical data on symptoms and patient characteristics collected by trained palliative care physicians and nurses. A clear weakness of the data is the high rate of missing values. This may be due to the circumstance that different SAPV providers have different documentation standards. For instance, some may assess the presence of confusion only in patients where it is clinically expected while others may do it as a default.

In terms of reliability, we expect the data to be comparable to prior years, but rather drastic changes are possible e.g. when financial compensation mechanisms get changed or during a pandemic situation.

The general characteristic and the symptom burden of the patient collective in our analysis was consistent with prior studies in the field. Patients with non-cancer disease were generally older, had a poorer performance status but showed no differences in pain intensity as compared to cancer patients $[19,20]$.

Our findings on time of survival for patients with and without cancer-disease are consistent with other studies in the field and show a significantly reduced survival time of patients with non-cancer disease [13]. As shown in Fig. 1 using a Kaplan-Meier curve, type of disease (cancer vs. non-cancer), Karnofsky-Score (10-30 vs. 40$100)$ and age (< 65 vs. $>85$ years) were all associated with significant differences in length of survival. As these factors were very likely interdependent, we adjusted for several variables in a Cox proportional hazard model. The model however showed that the type of disease (cancer vs. non-cancer) had no influence on length of survival (aHR: 1.03; $95 \%$ CI: 0.96-1.10). The strongest association for an increased hazard ratio was found for the following characteristics: moderate/severe weakness (aHR: 1.91; $95 \%$ CI: 1.27-2.86), Karnofsky score 10-30 (aHR: 1.80; $95 \%$ CI: 1.67-1.95), and age > 85 (aHR: 1.50; 95 \% CI: 1.37-1.64). Studies based on hospitalized cancer patients have identified similar risk factors in the past, mainly low performance scores and cancer-anorexia syndrome but also confusion and dyspnea which all correspond well with our results $[5,12]$. These results are an important addition to the existing knowledge base and clearly show that performance status and age are the most important predictors of a low life-expectancy in ambulatory palliative care.

It is a common assumption in palliative care, that patients with non-cancer disease are enrolled into palliative care too late or at least later than patients with cancerdisease. Our data however doesn't generally support this assumption. While non-cancer patients do spend less time in ambulatory palliative care, this is clearly due to their lower performance status and higher age upon enrollment. It may be possible that non-cancer patients just develop palliative care needs later in the last phase of life, an assumption that is supported by the very similar distribution of pain severity in cancer and noncancer patients upon enrollment. Patients with noncancer disease show a much higher rate of confusion but this is most likely due to their higher age, an assumption that is supported by the drop in the HR for confusion after adjustment for age and other factors. We therefore hypothesize that patients with non-cancer disease may not be generally referred to SAPV too late in relation to pain. It remains unclear if the lower performance status upon enrollment is a sign of delayed enrollment or a cofactor of the non-cancer patients' higher age. Qualitative research into the functional burden on quality-of-life of cancer and non-cancer patients in SAPV might be helpful to answer this question. 


\section{Conclusions}

Performance status is the most important influencing factor for a decrease in survival time in patients in ambulatory palliative care. Old age and the presence of several symptoms including loss of appetite and confusion are secondary influencing factors for a decreased survival time. Survival time is not influenced by the type of disease (cancer vs. non-cancer). This should be kept in mind when discussing prognosis with a patient and his or her family. Albeit it should be noted, that survival time is only one side of the medal, the other being quality-of-life.

We found no evidence that patients with non-cancer disease who do get admitted to SAPV, are admitted too late. They do not suffer from pain more than patients with cancer disease upon enrollment. We therefore assume that the SAPV may be rather well timed for those patients with non-cancer disease who receive it.

Further investigation should focus more on outcome criteria (e.g. quality-of-life) and should correlate those outcome criteria with length of survival in order to better investigate the important balance of life-expectancy and quality-of-life.

Declarations.

GmbH, Palliativteam SAPV RheinErft GmbH, Regionales Gesundheitsnetz Leverkusen eG, SAPV Team Solingen GmbH, SAPV Wuppertal GmbH, SAPVKrefeld GbR, SAPV-Team NoPaiN GmbH.

\section{Acknowledgements}

We thank VSTN e.V. and the data-providing SAPV services for their contribution: Home Care Städteregion Aachen gGmbH, HomeCare Linker Niederrhein gGmbH, Palliativ Care Team Kreis Heinsberg, Palliativ Netzwerk Niederrhein GmbH, Palliative Care Duisburg eG, Palliative Care Team Düsseldorf, Palliative-Care-Team Oberhausen, Palliativteam SAPV Köln Rechtsrheinisch.

\section{Authors' contribution}

JJ, KW, MP and UG designed the. UG, TJ and KH supervised data collection and performed quality control of the data. MP and JJ performed statistical analysis. JJ, UG, KW, MP, BE, TJ and KH discussed implications of the results and possible bias and contributed to the drafting of the paper. All authors read and approved the final manuscript.

\section{Funding}

There was no external funding for this study. Open Access funding enabled and organized by Projekt DEAL.

\section{Availability of data and materials:}

The datasets generated and analysed during the current study are available from the corresponding author upon reasonable request.

\section{Declarations}

\section{Ethics approval and consent to participate:}

The ethics committee of the North Rhine Medical Association reviewed the project and expressed no ethical, legal or data protection concerns (process number 57/2017). The ethics committee waved the need for patients consent to participate as routine treatment data was extracted and immediately anonymized upon extraction. All participating SAPV providers (data holders) gave their consent for data extraction and scientific analysis in written form.
Consent for publication

Not applicable.

\section{Conflict of interest}

Authors declare no conflict of interest.

\section{Author details}

${ }^{1}$ Institute of General Practice and Interprofessional Care Witten/Herdecke University, Alfred-Herrhausen-Straße 50, 58453 Witten, Germany.

${ }^{2}$ Department of Medical Biometry, Informatics and Epidemiology (IMBIE), University Hospital Bonn, Sigmund-Freud-Str. 25, 53127 Bonn, Germany. ${ }^{3}$ VSTN e.V. (Association of SAPV Teams in North Rhine), Venloer Straße 40, 41751 Viersen, Germany. ${ }^{4}$ Division of General Practice, Department of Health Services Research, Carl von Ossietzky University of Oldenburg, 26129 Oldenburg, Germany.

Received: 10 December 2020 Accepted: 28 April 2021

Published online: 17 May 2021

\section{References}

1. Pastrana $T$, Jünger $S$, Ostgathe $C$, Elsner $F$, Radbruch L. A matter of definition - key elements identified in a discourse analysis of definitions of palliative care. Palliative Medicine. 2008;22:222-32. doi:https://doi.org/10.11 77/0269216308089803.

2. Bakitas MA. Self-determination: analysis of the concept and implications for research in palliative care. Can J Nurs Res. 2005:37:22-49.

3. Daas $\mathrm{N}$ den, den Daas $\mathrm{N}$. Estimating length of survival in end-stage cancer: A review of the literature. Journal of Pain and Symptom Management. 1995; 10:548-55. doi:https://doi.org/10.1016/0885-3924(95)00103-6.

4. Stone PC, Lund S. Predicting prognosis in patients with advanced cancer. Annals of Oncology. 2007;18:971-6. doi:https://doi.org/10.1093/a nnonc/mdl343.

5. Maltoni M, Caraceni A, Brunelli C, Broeckaert B, Christakis N, Eychmueller S, et al. Prognostic Factors in Advanced Cancer Patients: Evidence-Based Clinical Recommendations-A Study by the Steering Committee of the European Association for Palliative Care. Journal of Clinical Oncology. 2005; 23:6240-8. doi:https://doi.org/10.1200/jco.2005.06.866.

6. Viganò A, Dorgan M, Buckingham J, Bruera E, Suarez-Almazor ME. Survival prediction in terminal cancer patients: a systematic review of the medical literature. Palliative Medicine. 2000;14:363-74. doi:https://doi.org/10.1191/02 6921600701536192.

7. Weeks JC, Cook EF, O'Day SJ, Peterson LM, Wenger N, Reding D, et al. Relationship between cancer patients' predictions of prognosis and their treatment preferences. JAMA. 1998:279:1709-14.

8. Daugherty CK, Hlubocky FJ. What Are Terminally III Cancer Patients Told About Their Expected Deaths? A Study of Cancer Physicians' Self-Reports of Prognosis Disclosure. Journal of Clinical Oncology. 2008;26:5988-93. doi: https://doi.org/10.1200/jco.2008.17.2221.

9. Gordon EJ, Daugherty CK. "Hitting you over the head": oncologists' disclosure of prognosis to advanced cancer patients. Bioethics. 2003;17: 142-68.

10. Christakis NA, Iwashyna TJ. Attitude and Self-reported Practice Regarding Prognostication in a National Sample of Internists. Archives of Internal Medicine. 1998;158:2389. doi:https://doi.org/10.1001/archinte.158.21.2389.

11. Christakis NA, Lamont EB. Extent and determinants of error in doctors' prognoses in terminally ill patients: prospective cohort study. BMJ. 2000;320: 469-72.

12. Glare $P$, Sinclair $C T$, Stone $P$, Clayton JM. Predicting survival in patients with advanced disease. Oxford Medicine Online. 2015. doi:https://doi.org/10.1 093/med/9780199656097.003.0007.

13. Bennett Ml, Ziegler L, Allsop M, Daniel S, Hurlow A. What determines duration of palliative care before death for patients with advanced disease? A retrospective cohort study of community and hospital palliative care provision in a large UK city. BMJ Open. 2016;6:e012576. doi:https://doi.org/1 0.1136/bmjopen-2016-012576.

14. Freytag A, Krause M, Bauer A, Ditscheid B, Jansky M, Krauss S, et al. Study protocol for a multi-methods study: SAVOIR - evaluation of specialized outpatient palliative care (SAPV) in Germany: outcomes, interactions, regional differences. BMC Palliat Care. 2019;18:12.

15. Spezialisierte ambulante Palliativversorgung (SAPV). https://www.dgpallia tivmedizin.de/allgemein/sapv.html. Accessed 24 Feb 2021. 
16. Nordrhein KV. Die Kassenärztliche Vereinigung Nordrhein. 2020. (Association of Statutory Health Insurance Physicians North Rhine) https://www.kvno. de/40ueberUns/index.html. Accessed 24 Feb 2021.

17. Reporting standards: Standard used to collect data: The Strengthening the Reporting of Observational Studies in Epidemiology (STROBE) Statement: guidelines for reporting observational studies. doi:https://doi.org/10.7554/ elife.08500.009.

18. Landesamt für Statistik NRW (Federal Bureau of Statistics NRW). https:// www.t.nrw/statistik/eckdaten/lebendgeborene-und-gestorbene-956. Accessed 24 Feb 2021.

19. Ostgathe C, Alt-Epping B, Golla H, Gaertner J, Lindena G, Radbruch L, et al. Non-cancer patients in specialized palliative care in Germany: what are the problems? Palliat Med. 2011;25:148-52.

20. Bostwick D, Wolf S, Samsa G, Bull J, Taylor DH Jr, Johnson KS, et al. Comparing the Palliative Care Needs of Those With Cancer to Those With Common Non-Cancer Serious Illness. J Pain Symptom Manage. 2017;53: 1079-84.e1.

\section{Publisher's Note}

Springer Nature remains neutral with regard to jurisdictional claims in published maps and institutional affiliations.

Ready to submit your research? Choose BMC and benefit from:

- fast, convenient online submission

- thorough peer review by experienced researchers in your field

- rapid publication on acceptance

- support for research data, including large and complex data types

- gold Open Access which fosters wider collaboration and increased citations

- maximum visibility for your research: over $100 \mathrm{M}$ website views per year

At $\mathrm{BMC}$, research is always in progress.

Learn more biomedcentral.com/submissions 